\title{
Visual Status and Visual Challenges of Persons with Albinism in A Metropolitan City of Niger Delta Region, Nigeria
}

\author{
Alfred A Onua ${ }^{1}$ and Ihunanya Ibanga ${ }^{2 *}$ \\ ${ }^{1}$ Department of Ophthalmology, University of Port Harcourt, Nigeria, West Africa \\ ${ }^{2}$ Mecure Healthcare Limited Eye Center, Lagos, Nigeria, West Africa \\ * Corresponding Author: Ihunanya Ibanga, Mecure Healthcare Limited Eye Center, \\ Lagos, Nigeria, West Africa.
}

DOI: 10.31080/ASOP.2020.03.0100
Received: February 17, 2020

Published: February 27, 2020

(C) All rights are reserved by Alfred A Onua and Ihunanya Ibanga.

\begin{abstract}
Aim: To determine the visual status and visual challenges of 'Persons with Albinism' (PWA) in Port Harcourt, Niger Delta, Nigeria. Methods: This was a descriptive cross-sectional study of 116 persons with albinism in Port Harcourt over a five-month period. Visual assessments were used to ascertain the participants visual acuity, visual needs and challenges. Detailed ocular examination of the visual acuity, anterior and posterior segments were carried out. Data was analysed using SPSS version 25 . Chi square and Independent sample $\mathrm{T}$ test were the statistical tools. A p-value $\leq 0.05$ was considered statistically significant.

Results: Forty-four participants (37.9\%) were males. Male to female ratio was 1:1.6. The mean age of participants was $26.12 \pm 14.32$ years (range: 5-56 years). Difficulty in performing near work was the major complaint of the study participants 96 (82.7\%). Most eyes were visually impaired for both distance (98.3\%) and near vision (96.6\%). With refraction and Low Vision Aid (LVA), there was significant improvement of the mean VA by $2-3$ acuity lines and 6 acuity lines respectively $(p=0.000)$. All the examined eyes had fundus hypo-pigmentation, $91.4 \%$ had iris trans-illumination, $86.2 \%$ had nystagmus and $34.4 \%$ had strabismus.

Conclusion: Majority of the study participants (98.3\%) had reduced near and distance visual acuity There was a significant improvement in the participants vision with correction $(\mathrm{p}=0.00)$. Refraction with appropriate correction of near and distance vision should therefore be part of the routine ophthalmic services for PWA.
\end{abstract}

Keywords: Visual Status; Persons with Albinism; Niger Delta Region

\section{Introduction}

Albinism is an inherited disorder characterised by a decrease or absence of pigment in the hair, eyes and skin of affected individuals resulting from disruption in melanin pigment synthesis as a result of mutations in various enzymes and membrane proteins [1]. Albinism could be Oculocutaneous albinism (OCA) and Ocular albinism (OA). In Oculocutaneous albinism, the hair, skin and eyes are affected while in Ocular albinism the features is confined to the eyes and visual system [2]. The most common variants of albinism and their responsible genes are: Ocular albinism (OA1gene), OCA1 (Tyrosine TYR gene), OCA2/Brown OCA (P gene)- which is the commonest in Africa, OCA3/Rufous OCA (Tyrosine-related protein-1, TRP-1 gene) and OCA4 (SLC45A2 gene) [3-5].

In Nigeria, the prevalence of albinism is estimated at 1:15000 [6]. Nigeria has the largest population of albinos in West Africa $[6,7]$ and the Southern Nigeria is mostly affected [6].

The inherent disruption of melanin synthesis in albinism, results in abnormality in the development of the visual system leading to several visual deficits including delayed visual maturation, nystagmus, iris trans-illumination, strabismus, optic nerve hypo- 
plasia, abnormal fovea, abnormal decussation of the optic chiasm, impaired colour vision, reduced contrast sensitivity and stereoacuity [8-10].

\section{Materials and Methods}

This was a descriptive cross-sectional study of 116 persons (232 eyes) with albinism (PWA) recruited from The Albinism Foundation in Port Harcourt City, Rivers State, Nigeria over a fivemonth period (from November 2016 to March 2017).

A semi-structured pretested questionnaire was used to record age, gender, relevant ocular and medical history, visual acuity and clinical examination findings. Subjective and objective visual assessments were used to ascertain the participants visual acuity, visual needs and challenges. Distance visual acuity was assessed using the Early Treatment Diabetic Retinopathy Study (ETDRS) chart placed at 4 metres under standard illumination and recorded in Logarithm of the Minimum Angle of Resolution (log MAR) units while the near acuity was assessed using Radner Reading Chart at $40 \mathrm{~cm}$.

A detailed ophthalmic examination of the anterior segment and assessment of iris transillumination with dilated fundus examination for the macula was done. Foveal hypoplasia was then diagnosed based on the absence of foveal reflex/depression while macular transparency was diagnosed based on the prominence of choroidal vessels in the macula.

Data obtained was analyzed using the Statistical Package for Social Sciences (SPSS version 25, SPSS Inc., IBM, USA). Simple sta- tistics such as means and frequencies were determined. Independent sample $\mathrm{T}$ test and the Chi square test used to compare the appropriate variables. A p-value $\leq 0.05$ was considered statistically significant.

\section{Results}

There were $44(37.9 \%)$ males and $72(62.1 \%)$ females with a male to female ratio of $1: 1.6$. The mean age of participants was $26.1 \pm 14.3$. Age range was 5 to 56 years. The modal age group was 31 - 40 years and accounted for $25.9 \%$ of the study participants (Table 1).

Fifty percent of the study participants had secondary education. Most participants were either students ( $n=44,37.9 \%)$ or unemployed $(n=26 ; 22.4 \%)$; this was statistically significant $(p=$ 0.001 ) (Table 2 and 3).

\begin{tabular}{|l|c|c|c|}
\hline $\begin{array}{l}\text { Age Groups } \\
\text { (Years) }\end{array}$ & $\begin{array}{c}\text { Male } \\
\text { Number (\%) }\end{array}$ & $\begin{array}{c}\text { Gender Female } \\
\text { Number (\%) }\end{array}$ & $\begin{array}{c}\text { Total } \\
\text { Number (\%) }\end{array}$ \\
\hline$<10$ & $10(8.6)$ & $12(10.3)$ & $22(19)$ \\
\hline $11-20$ & $8(6.9)$ & $16(13.8)$ & $24(20.7)$ \\
\hline $21-30$ & $8(6.9)$ & $14(12.1)$ & $22(19)$ \\
\hline $31-40$ & $14(12.1)$ & $16(13.8)$ & $30(25.9)$ \\
\hline $41-50$ & $2(1.7)$ & $12(10.3)$ & $14(12.1)$ \\
\hline $\begin{array}{l}51 \text { and } \\
\text { above }\end{array}$ & $2(1.7)$ & $2(1.7)$ & $4(3.4)$ \\
\hline Total & $44(37.9)$ & $72(62.1)$ & $116(100.0)$ \\
\hline
\end{tabular}

Table 1: Age and Gender Distribution of Study Subjects.

\begin{tabular}{|l|c|c|c|c|c|}
\hline Occupation & \multicolumn{3}{|c|}{ Educational status No. (\%) } & & Chi square (p value) \\
\hline & Primary & Secondary & Tertiary & Total & \\
\hline Student & $24(20.7)$ & $12(10.3)$ & $8(6.9)$ & $44(37.9)$ & $35.94(* 0.001)$ \\
\hline Unemployed & $2(1.7)$ & $22(19.0)$ & $2(1.7)$ & $26(22.4)$ & \\
\hline Artisan & $0(0.0)$ & $2(1.7)$ & $0(0.0)$ & $2(1.7)$ & \\
\hline Apprentice & $0(0.0)$ & $2(1.7)$ & $0(0.0)$ & $2(1.7)$ & \\
\hline Business owner & $2(1.7)$ & $14(12.1)$ & $2(1.7)$ & $18(15.5)$ & \\
\hline Civil servant & $0(0.0)$ & $6(5.2)$ & $8(6.9)$ & $14(12.1)$ & \\
\hline Professional career & $0(0.0)$ & $0(0.0)$ & $10(8.6)$ & $10(8.6)$ & \\
\hline Total & $28(24.1)$ & $58(50.0)$ & $30(25.9)$ & $116(100.0)$ & \\
\hline
\end{tabular}

Table 2: Socio-Demographic Characteristics of PWA. 


\begin{tabular}{|l|c|c|}
\hline \multirow{2}{*}{ Visual Acuity Categories (LogMAR; Snellen Equivalent) } & Presenting VA & Best Corrected VA \\
\cline { 2 - 3 } & Freq. (\%) & Freq. (\%) \\
\hline Distance Visual Acuity & & \\
\hline Normal vision $(\geq 0.3 ; 6 / 12)$ & $4(1.7)$ & $20(8.6)$ \\
\hline Mild VI $(<0.3-\geq 0.48 ; 6 / 12-6 / 18)$ & $8(3.4)$ & $24(10.3)$ \\
\hline Moderate VI $(<0.48-\geq 1.0 ; 6 / 18-6 / 60)$ & $172(74.1)$ & $176(75.9)$ \\
\hline Severe VI $(<1.0-\geq 1.3 ; 6 / 60-3 / 60)$ & $24(10.4)$ & $4(1.7)$ \\
\hline Blindness $(<1.3-\geq 2.0 ; 3 / 60-$ NLP) & $24(10.4)$ & $8(3.4)$ \\
\hline Total & $232(100)$ & $232(100)$ \\
\hline Near Visual Acuity & & \\
\hline Normal vision $(\geq 0.3 ;$ N6) & $8(3.4)$ & $60(25.9)$ \\
\hline Mild VI $(<0.3-\geq 0.48 ;$ N6-N10) & $8(3.4)$ & $36(15.5)$ \\
\hline Moderate VI $(<0.48-\geq 1.0 ;$ N10- N32) & $162(69.8)$ & $134(57.8)$ \\
\hline Severe VI $(<1.0-\geq 1.3 ;$ N32- N63) & $30(13)$ & $2(0.9)$ \\
\hline Blindness $(<1.3-\geq 2.0 ;$ N63- N320) & $24(10.4)$ & $0(0.0)$ \\
\hline Total & $232(100)$ & $232(100)$ \\
\hline
\end{tabular}

Table 3: Frequency Distribution of Presenting and Best Corrected Visual Acuity in 232 eyes.

Legend: Freq- Frequency; VI- Visual Impairment.

A total of 228 (98.3\%) eyes had visual impairment for presenting distance vision while 224 (96.6\%) eyes were visually impaired for near. Over $74 \%$ of the participants had moderate visual impairment for presenting distance and about $69 \%$ had moderate near vision impairment. After refraction and subjective corrections, the number of eyes with normal vision increased from 4 (1.7\%) eyes to $20(8.6 \%)$ eyes for distance vision and from 8 (3.4\%) eyes to $60(25.9 \%)$ eyes for near vision; while the number of blind eyes reduced from $24(10.4 \%)$ to $8(3.4 \%)$ for distance vision.

All the eyes of the study participants (232 eyes) had macular transparency (prominent choroidal vessels), fundus hypopigmentation and foveal hypoplasia. Nystagmus was present in 200 eyes $(86.2 \%)$ while iris trans-illumination was seen in 212 eyes (91.4\%). Strabismus was noted in only 80 (34.5\%) eyes.

\begin{tabular}{|l|c|}
\hline Ocular Finding & Frequency (n) Percentage (\%) \\
\hline Nystagmus & 20086.2 \\
\hline Strabismus & 8034.5 \\
\hline Pterygium & 31.3 \\
\hline Iris transillumination & 21291.4 \\
\hline Fundus hypopigmentation & 232100 \\
\hline Macular transparency & 232100 \\
\hline Foveal hypoplasia & 232100 \\
\hline
\end{tabular}

Table 4: Ocular findings in the individual eyes of the study participants.

\section{Discussion}

\section{Socio-demography}

In this study, there were 44 (37.9\%) males and 72 (62.1\%) females with a male to female ratio of 1:1.6. The mean age of participants was $26.1 \pm 14$.3. Age range was 5 to 56 years. The modal age group was 31 - 40 years and accounted for $25.9 \%$ of the study participants (Table 1). Many study participants were either students or unemployed. This study compares with that of by Udeh., et al. in Enugu, Nigeria where the mean age was 23.46 years with female preponderance and majority of her participants were either students or unemployed [11]. Studies in different parts of Nigeria also observed similar socio-demographic characteristics among the study participants $[12,13]$. In Cameroun and Nepal, similar age ranges of study participants have been reported. Although in the United Kingdom much higher mean age of 42 years was reported [14]. The observed differences in the mean age of the study participants may be due to differences in the levels of development, the ease of availabilities and accessibilities of health care in the different countries. Stigmatization, visual impairment and physical appearance play significant roles in the high unemployment rate and the poor or lack of social interaction. In this respect, females are more vulnerable as they may not meet the societal norm for marriage in a male-dominated society where it is always the man who seeks out a wife. This could explain the female preponderance in this study population. 
In this study, fifty percent of the study participants had secondary education, however, $39.7 \%$ were secondary school dropouts (Table 2). This is in contrast to an earlier study in Enugu, South East Nigeria where more than half of the participants had tertiary education [11]. The reason for this difference could be because The Albinism Foundation (TAF), Enugu chapter, has been in existence far longer than the Port Harcourt branch and its members have better access to spectacles, low vision aids and other social benefits from the support group which in turn may have encouraged them to progress with their educational pursuit up to the tertiary institutions of higher learning. The recent rising cost of tertiary education and the financial burden of purchasing low vision aids also make it more frustrating for a PWA to continue with his/her educational career. Therefore, increase in public funding and social awareness is needed to maximise the potentials of a PWA and enhance their employable skills.

\section{Visual impairment and best corrected visual acuity}

Our study revealed a total of 228 (98.3\%) eyes with various degrees of visual impairment for presenting distance vision and 224 (96.6\%) eyes visually impaired for near. Over $74 \%$ of the participants had moderate visual impairment for presenting distance and about $69 \%$ had moderate near vision impairment. After refraction and subjective corrections, the number of eyes with normal vision increased from $4(1.7 \%)$ eyes to $20(8.6 \%)$ eyes for distance vision and from $8(3.4 \%)$ eyes to $60(25.9 \%)$ eyes for near vision; while the number of blind eyes reduced from 24 (10.4\%) to 8 (3.4\%) for distance vision (Table 3).

In this study, presenting (uncorrected) and best corrected visual acuities were analysed based on WHO classification of visual impairment $[15,16]$. Our observations in this study is similar to the results reported by Udeh., et al. and Ajose., et al. in other parts of Nigeria $[11,13]$. Other developing countries with similar socioeconomic status such as Nepal, Cameroun and Malawi also had similar findings [17-19]. It has been postulated that the subnormal presenting visual acuity may be due to delayed visual maturation, foveal hypoplasia, nystagmus, strabismus and iris trans-illumination. Anderson., et al. in the United States of America however, reported a better mean uncorrected distance and near visual acuity of 0.73 logMAR (6/32 Snellen) and 0.31 logMAR (N6) respectively [20]. This could be because of better socioeconomic disposition of the citizens and easier availability of quality health care making it possible to access low vision aids (LVA). With LVA, persons with albinism can achieve their full potential.
In this study, it was observed that despite the recorded improvement with refraction, there was still overall subnormal vision in participants and the reason may be due to associated varying degrees of foveal hypoplasia and amblyopia. However, with low vision aid, there was further improvement in their visual function. These findings further buttress the need for promotion of early optical intervention especially low vision aids in persons with albinism as this would improve visual acuity, quality of life and therefore ability to achieve their full potentials in life.

\section{Ocular challenges of PWA}

People living with albinism in Nigeria have various visual challenges that affect their activities of daily living and also compromise their level of social engagement. This study reported the following ocular findings in 116 persons with albinism in Port Harcourt: All the participants (116 people with 232 eyes) had macular transparency (prominent choroidal vessels), fundus hypopigmentation and foveal hypoplasia. Nystagmus was present in 200 eyes (86.2\%) while iris trans-illumination was seen in 212 eyes (91.4\%). Strabismus was noted in only 80 (34.5\%) eyes.

Udeh., et al. reported similar posterior segment finding in their study at Enugu, Nigeria [11]. Other studies in Nepal and the USA also had similar results $[17,21,22]$. The reason for the fundus hypopigmentation and foveal hypoplasia is due to the reduced melanin pigmentation which is directly responsible for foveal hypoplasia and hypopigmentation. Nystagmus was present in $86.2 \%$ of the eyes, similar to studies in Nepal and the USA [17,21]. However, Udeh., et al. reported 100\% nystagmus in their study population [11]. This higher percentage of nystagmus in the study of Udeh., et al. may not be unconnected with the inclusion criteria for nystagmus which included minimal nystagmus detectable by slit lamp examination unlike this study where only those with obvious nystagmus were considered. Other studies with similar methodology as in the study of Udeh., et al. also reported universal presence of nystagmus [19,21,22]. Underdevelopment of the fovea and delayed visual maturation seen in PWA is considered to be responsible for the development of nystagmus. Nystagmus and iris trans-illumination were absent in all the eyes with normal vision but present in all eyes that were either blind or severely visually impaired.

In almost all the eyes, varying degrees of iris trans-illumination was observed and this is due to the varying amount of melanin pigment present in every PWA. This is consistent with findings by Udeh., et al. but different from other studies where iris trans- 
illumination was noted in all participants [11,17,21,23]. The reason for the difference may be because the earlier studies were all hospital-based [17, 21, 23].

In this study, strabismus was noted in 40 (34.5\%) participants and this was similar to other studies [24,25,26]. Strabismus is thought to result from abnormal decussation at the optic chiasm leading to misrouting of the visual pathway. A much lower frequency was however observed by Udeh., et al. and this may be because most participants in her study were more educated and therefore might have sought optical correction earlier thereby improving visual outcome [11]. Exotropia was the most common type of strabismus noted, similar to Udeh's study but different from studies $[11,22,26]$.

This study noted that the more the number of associated ocular features with albinism present in an individual, the more there was significant effect on vision. The higher the number of features present, the worse the visual acuity.

\section{Conclusion}

There is significant visual challenge in Persons with Albinism. Over ninety-eight of participants in this study, had reduced near and distance visual acuity. However, there was a significant improvement in the participants vision with refraction and subsequent subjective correction. Refraction with appropriate correction of near and distance vision and the dispensing of Low Vision Aids should therefore be part of the routine ophthalmic services for PWA.

\section{Consent and Ethical Approval}

The study was approved by the Health Research Ethics Committee of The University of Port Harcourt Teaching Hospital and it followed the tenets of the Declaration of Helsinki. All participants consented to the study.

\section{Competing Interests}

Authors have declared that no competing interests exist.

\section{Bibliography}

1. Oetting WS and King RA. "Molecular basis of albinism: Mutations and polymorphisms of pigmentation genes associated with albinism". Human Mutation 13.2 (1999): 99-115.

2. Gronskov K., et al. "Oculocutaneous albinism". Orphanet Journal of Rare Diseases 2 (2007): 43.
3. Kamaraj B and Purohit R. "Mutational Analysis of TYR gene and its structural consequences in OCA1A". Gene 513.1 (2012): $5-9$.

4. Manga P., et al. "Biology and genetics of oculocutaneous albinism and vitiligo - Common pigmentation disorders in southern Africa". South African Medical Journal 103.12 (2013): 984988.

5. Kamaraj B and Purohit R. "Mutational analysis of oculocutaneous albinism: A compact review". BioMed Research International 204.4 (2014):1-10.

6. Okoro AN. "Albinism in Nigeria”. British Journal of Dermatology 92.5 (1975): 485-492.

7. Hong ES., et al. "Albinism in Africa as a public health issue". BMC Public Health 6 (2006): 212-217.

8. Hertle R and Cochran M. "Clinical Contrast Sensitivity (CS) Testing in Patients with Infantile Nystagmus Syndrome (INS) Before and After Eye Muscle Surgery". Investigative Ophthalmology and Visual Science 56.7 (2015): 3999-4001.

9. Conley J., et al. "The optic nerve and retinal vasculature in albinism: Normal or abnormal?" Journal of AAPOS 17.1 (2013): e12-e13.

10. Summers CG. "Albinism: Classification, Clinical Characteristics and Recent Findings". Optometry and Vision Science 86.6 (2009): 659-662.

11. Udeh NN., et al. "Prevalence and Profile of Ophthalmic Disorders in Oculocutaneous Albinism: A Field Report from SouthEastern Nigeria”. Journal of Community Health 39.6 (2014): 1193-1199.

12. Ikuomola A. "Socio-Cultural Conception of Albinism and Sexuality Challenges among Persons with Albinism (PWA) in South- West, Nigeria". Indian Journal of Animal Health 4.14 (2015): 189-208.

13. Ajose F., et al. "Visual Defect in Oculocutaneous Albinism is Not Associated with Gross Structural Anomaly". Journal of Clinical and Experimental Dermatology Research 5.4 (2014): 1-4.

14. Von Dem Hagen EAH., et al. "Identifying human albinism: A comparison of VEP and fMRI". Investigative Ophthalmology and Visual Science 49.1 (2008): 238-249. 
15. Healey N., et al. "Are worldwide albinism prevalence figures an accurate reflection? An incidental finding from a Northern Ireland study". British Journal of Ophthalmology 98.7 (2014): 990-994.

16. King R., et al. "Abnormalities of pigmentation". In: Rimoin D, Connor J, Pyeritz R, Korf B (eds) Emery and Rimoin's Principles and Practice of Medical Genetics. Churchill Livingstone Elsevier, Philadelphia, 5th edition (2007): 3380-3427.

17. Khanal S., et al. "Visual deficits in Nepalese patients with oculocutaneous albinism". Journal of Optometry 9.2 (2016):102109.

18. Eballé AO., et al. "Refractive errors in Cameroonians diagnosed with complete oculocutaneous albinism". Clinical Ophthalmology 7 (2013): 1491-1495.

19. Schulze SM., et al. "Refractive errors, visual impairment, and the use of low-vision devices in albinism in Malawi". Graefe's Archive for Clinical and Experimental Ophthalmology 253.4 (2015): 655-661.

20. Anderson J., et al. "Efficacy of spectacles in persons with albinism”. Journal of AAPOS 8.6 (2004): 515-520.

21. Preising MN., et al. "Screening of TYR, OCA2, GPR143, and MC1R in patients with congenital nystagmus, macular hypoplasia, and fundus hypopigmentation indicating albinism". Molecular Vision 17 (2011): 939-948.

22. Kutzbach BR., et al. "Evaluation of vision-specific quality-oflife in albinism". Journal of AAPOS 13.2 (2009): 191-195.

23. Holmström G., et al. "Optical coherence tomography is helpful in the diagnosis of foveal hypoplasia". Acta Ophthalmologica 88.4 (2010): 439-442.

24. Sjöström A., et al. "Subnormal Visual Acuity (SVAS) and albinism in Mexican 12-13-year-old children". Documenta Ophthalmologica 108.1 (2004): 9-15.

25. Wolf B., et al. "Comparison of clinical findings in pediatric patients with albinism and different amplitudes of nystagmus". Journal of AAPOS 9.4 (2005): 363-368.

26. Dorey SE., et al. "The clinical features of albinism and their correlation with visual evoked potentials". British Journal of Ophthalmology 87.6 (2003): 767-772.

\section{Assets from publication with us}

- Prompt Acknowledgement after receiving the article

- Thorough Double blinded peer review

- Rapid Publication

- Issue of Publication Certificate

- High visibility of your Published work

Website: www.actascientific.com/

Submit Article: www.actascientific.com/submission.php

Email us: editor@actascientific.com

Contact us: +919182824667 